\title{
Physical approach to possession and use
}

\begin{abstract}
In this study, the starting point is the well-known physical laws applied to human social life. On the basis of natural laws human actions are considered and through the prism of physical laws such concepts as use and possession are defined. A parallel is drawn between such a representation of these concepts and those conflicting views that are available in the literature regarding the concept of property. To complete the definitions of use and possession nature is introduced as a fictitious owner. And on this basis, the positive possibility of a theoretical solution to the problem of initial assignment is shown.
\end{abstract}

Again, on the basis of physical laws, the fundamental concept of [human] needs is introduced. It is shown that the collision of people's needs on the same thing allows uniform classifying property defined in literature as the relationship between a person and a thing or as the relationship between people because of a thing.

Considering the relationship between two human beings through needs and costs, as a natural necessity, people inevitably renounce their claims to possess and use certain things in favor of other people. It is shown that this refusal forms the right of those people in whose favor this refusal is carried out to possess and use things. The right of one is the refusal of all others to own and use the thing. It is shown that the right was ensured and will always be ensured by force. The use or threat of the use of force is something that can reliably ward off a person from the unbridled realization of his needs. In the process of the formation of mankind, nature itself forces people to organize into communities that can oppose their individual members and their associations with significantly greater power. The whole, as a rule, is stronger than its part. And it is society that can reliably ensure the exercise of rights for its members.

Natural laws also make it possible to resolve, on the basis of the concept of law, as a renunciation of possession and use, the issue of belonging to what nature gives us. These are natural resources and the human body. It is shown that the human body should belong to the person himself, and the resources to all members of society equally. The affiliation of all other things produced by man can be unambiguously determined within the framework of contractual relations between members of society, their associations and society as a whole.

Since the right of everyone is ensured by the society, and, therefore, by each member of the society individually, a necessary condition for membership is understanding and recognition of the rights of certain things to other members of the society. And this may be the main criterion for joining full members of society, as opposed to the commonly used age criterion, which works on the bulk of people, but gives failures in many special cases. A typical example of such cases is the deprivation or infringement of the rights of persons of full legal age, but committed acts that are called unlawful in society.

As part of the research on ownership issues, ownership is considered. It is shown that the necessary tool for using the objects of co-ownership is the voting of co-owners. A special case of coownership, when all co-owners have equal shares in co-ownership, is indistinguishable from what is called democracy. It is shown that voting in general and democracy in particular, as procedures for aggregating preferences, can have a positive decision, in refutation of the universality of the conclusion of Arrow's theorem.

Keywords: use, possession, needs, right, coownership 
Let's consider the interaction of human with outside world on a physical level. This interaction is carried out through the receptor system responsible for the five known sensory organs. In human body, there are about a billion receptors that ensure the reception and transmission of incoming signals through the nervous system. The ultimate receiver and decision maker regarding the response to receptor signals is a brain. Some signals can be processed without participation of a brain, for example, in a spinal cord. However, such processing does not imply a decision, but only reduces to implementation an existing program of a known reaction to known effects. These are instinctive and reflex actions. A body works like a machine. If the effect is recognized as known, it launches a readymade program of reaction to this effect. The brain, on the other hand, can make decisions on reactions to impacts, for which there is no reaction program. The very task of making such a decision is of particular interest. But in this study we will not touch on this. Moreover, for our study it doesn't even matter if a person has a brain and how exactly she makes decisions on response to impacts. The impact enters the human body, then it is somehow processed there and some kind of reaction follows. First of all, we will be interesting in processing the received impact in the most general form.

First of all, the signal received in the brain goes through the evaluation stage. A human needs to develop its attitude towards the impact, whether it is good or a threat for her. The price of such a decision can be very high. A human may lose something very useful to her or may receive great harm or even death. The impact assessment process itself is not available to an outside observer. Everyone can judge it only on their own experience. But the human reaction to the impact is quite observable. If a person evaluates the impact as positive, then the reaction to it will be such as to encourage prolongation of exposure or even its enhancement, at least until the moment when it ceases to be assessed as positive. Conversely, if the assessment is negative, the person will try to reduce or even cease the impact. For example, a person can positively assess the impact of sunlight on his body by sunbathing on the beach. But after some time the sun's rays begin to have a negative impact and a person protects her body by covering with clothes or hiding in the shade.

It should be noted that although the human reaction is unambiguously connected with the assessment of the impact, this connection may not always be visible to an outside observer. This is caused by the fact that, as a rule, a person does not react to a single impact but to several impacts at once. Moreover a part of these effects may not even have come at the time of the reaction. For example, going to the dentist a person is guided not only by a negative assessment of toothache and not only by a negative assessment of future pain during treatment but mainly by a positive assessment of the future absence of pain and other benefits of healthy teeth. Although human actions are observable only an actor can reliably associate her actions with her assessment of certain impacts. Nevertheless such a connection is often traced. After all human actions are always aimed either at encouraging or to cease influences. And if a person acts unsophisticatedly it remains only to track what impacts are to be encouraged or ceased by person's actions.

Perhaps in some of his actions a person is not guided by external influences. Those it can be assumed that some human actions are in no way associated with any impact. And this is also a separate issue for research. Nevertheless of course influences play an important role in human life. Therefore we will examine the question of what the impacts are and where they come from. To do this we turn to physics as a science capable of answering these questions most fully, consistently and unequivocally.

From the point of view of physics all sensory receptors work on the same principle. They use the so-called electromagnetic interactions the theory of which was founded by the English scientist James Maxwell. In total four types of interactions are known - electromagnetic, gravitational, nuclear strong and weak. All they are exchange interactions and appear through exchange between bodies by so-called quanta of interaction. For electromagnetic interactions such quanta are well-known photons. For gravitational - hypothetical gravitons. For strong nuclear - gluons. For weak nuclear - W \pm and Z0 bosons. 
The most obvious manifestation of electromagnetic interaction is in the work of organs of vision. The receptors of the eye perceive photons of the so-called visual range of the spectrum directly. Further on the basis of absorbed photons receptors form signals transmitted to the brain through the nervous system which a brain evaluates and responds to. Electromagnetic interactions are not so clearly observable in receptors of other senses. We know from the school course of physics that auditory receptors perceive sound air pressure. Air pressure manifests itself as impulses of air molecules and the frequency of their collisions with the ear membrane molecules. There is a primitive idea of such collisions as billiard balls. In fact as air molecule approaches the membrane molecule the electron shells of atoms begin to interact with each other. And they interact precisely via exchanging of quanta of electromagnetic interactions, i.e. by means of photons. Comparing vision with other senses, between a body that emitted the photon and the receptor of the eye that absorbed it there is quite a considerable distance comparable to the size of the human body, and in the case of the Sun and stars as emitting bodies the distance significantly exceeds the size of a human body. Whereas for all other senses the electromagnetic interaction is manifested on the scales of the distances between the molecules. However, in all cases we are dealing with electromagnetic interactions.

In fact it is not so important by means of what kind of interaction the sensory receptors work. It is important that this is an exchange interaction, and in addition to receptors that accept quanta there is always a body that emits these quanta. I.e. receptors perceive other physical bodies through influences. Any impact on receptors comes from a particular physical body. And if we talked above about the important role of influences in human life now we can already argue about the same role of physical bodies since they give rise to all impacts on receptors. But what happens with bodies and receptors in particular in such interactions? Again physics gives a definite answer. A quantum of interaction always has a certain energy. The body that emitted the quantum loses this energy. And the body that absorbed it acquires this energy. In our case it is a receptor. In physics there is the concept of the state of a physical body as energy and momentum and position at a certain point in definite time. Then the body that emits or absorbs the quantum of interaction changes its physical state. A change in the physical state in the macrocosm is appeared as an action of force and is described by well-known Newton's laws.

So, in order to get some kind of positive impact it is necessary that some physical body changes its states. And in order to confine external influences it is also necessary that some bodies change their states. In order for the bodies to change their states, some physical force must act on them. This power can be independent on human. In this case a person simply uses favorable influence or tries to isolate herself from the adverse impact. So a person swim in water or bathes under a waterfall or sunbathes in the sun, etc., or dresses up from the cold, uses an umbrella from the rain, builds a shelter from predators and enemies, etc. Also, a person can initiate (apply) a force to a body so that it changes its state in the necessary way to obtain the necessary impacts. I.e. a person uses bodies. At that bodies compulsory change their physical states.

\section{DEFENITION 1 (D1). The use of a physical body is a change in its physical state.}

It should also be noted that the phrase "use the physical body" is the only possible. It is impossible, for example, to say "to use not a physical body." The act of use necessarily involves the application of force to a physical and only to a physical body. For the same reason in a phrase "using something" only physical body can be as "something" and nothing else.

The process of use may take place and it can be potentially possible as well. Any physical body can potentially be in a multitude of states. Possibly this multitude can be infinite. Applying a certain force to a body one can transfer the body from one state to another initiating the necessary impacts from it. Possessing knowledge of what forces must be applied to a body in order to obtain the necessary result and having the ability to apply these forces a person has all the necessary conditions to be able to do this. Human has a certain power over the body. I.e. we come to another term the possession. 
DEFINITION 2 (D2). The possession of a physical body is the potential opportunity to implement or prohibit implementing some physical states of the body.

In nature all physical bodies constantly change their states, exchanging by quanta of various interactions with other bodies. So according to D1 all physical bodies are constantly in use by someone or somewhat. And this someone or something is far from always a person. It can be other living beings but mainly other inanimate matter, other physical bodies. This is all that we call the nature.

The terms "use" and "ownership" in economic science are used in combination "use / possession of property". In this connection, there is a temptation to associate the obtained definitions with property. Representatives of modern schools used to consider the property as a set of legal rights. One can mark schools of instrumentalism and formalism or conceptualism that rival each other [Bell \& Parchomovsky]. These two approaches seem so incompatible with each other that representatives of competing schools accuse each other of not understanding the subject of the study [Merrill \& Smith]. The instrumentalists prefer to avoid any special meaning of property, considering it as an aggregation of legal rights without distinguishing by which legal categories an aggregation occurs. Conceptualists deal with concepts derived from Roman law insisting on the supremacy of real and especially privileged rights including the right to alienate and use and transfer property [Honore]. For a more complete picture of the characteristics of a particular school see Bell \& Parchomovsky. There are also ideas about property as the quality of human relations such as the relationship between people because of things [Tsibulenko], or the relationship between a person and a thing [Marx \& Engels]. At that objects themselves, things, physical bodies are not considered as property at all. But neither law nor relationship nor method can be physical bodies. From the physical point of view the use of rights and relationships and method does not have physical sense if physical objects are not behind them. For example rights and relationships can be reflected in the form of some documents that can be considered as physical objects and which can be used. In these documents actions with other physical objects can be described, i.e. use of these facilities. The method is knowledge of what actions and what sequences of actions must be performed with some material objects in order to obtain the necessary result, namely the necessary impact on something or someone. In any case at first must be the use of a material body and only on basis of such a usage the rights, relations and other generalizing concepts can arise if to adhere to the materialistic approach.

Taking into account such contradictory ideas about ownership and foreseeing all the difficulties of incorporating into these ideas, mainly because of the opposition of representatives of those schools who may consider the argued in this article statements to be inconsistent with their ideas, we will not associate the constructions and conclusions of this article with property only tracing the parallels with it.

\section{Fictitious owner}

In accordance with D1 and D2 formally nature also possesses and uses material objects. And it uses and possesses many objects alone. These are objects that human has not yet learned to use or those that are out of human reach. Nature can also be regarded as a kind of fictitious user and owner.

Any material object can potentially be in many different states most likely an infinite number of states. To denote this whole set let's introduce the term "unlimited possession." To denote any subset of this set let's introduce the term "limited ownership". Then the sum of all disjoint limited possessions is equal to unlimited possession. Any object may be in limited possession of one or more people. In this case the rest of unlimited possession is in limited possession of a fictitious user, of nature. As one can see the introduction of a fictitious user is necessary to fulfill the condition of completeness of the definition of possession and seems at first glance useless. In fact it now becomes clear how to approach to the problem of initial assignment. In accordance with the foregoing a person can get in limited possession only those material objects that are already in limited possession of other human or in the 
limited or unlimited possession of nature. New material objects may arise as a result of human or natural activity. Regarding to human-nature relations let's define the initial appropriation as follows.

Definition 3 (D3). The initial appropriation is the seizure of limited possession from nature.

\section{The needs as motivation for use and possession}

So far we have examined the question "how does a person interact with the environment, with material objects?" Not unimportant are the answers to the questions "why does human interact with the environment?", "why should she use and possess material objects?". What is the incentive mechanism for use and possession?

In this case, we come to the concept of needs. And again, physics and its subsection synergetics will help us in this. According to the third law of thermodynamics any self-organizing system including human cannot exist without any influx of energy from outside. And this influx is impossible without interaction with other material bodies. It is from other bodies and precisely through interaction with them, i.e. through use, a person can receive the energy necessary for her existence. The need for such an influx determines at least the material needs of human. Whether a person has any other needs for example spiritual ones and what they consist of we will not consider. We only note that if these needs are realized through the use of material objects there is no fundamental difference in the manifestation of material and spiritual needs for our research.

So a living person always has needs in material objects otherwise she will not be alive. A person realizes her needs through the use of material objects. But needs are only a potential i.e. something not yet accomplished. In this sense needs would seem to be close to possession. But there is a significant difference. A person can experience and often feels the need for those material objects that she does not possess. These can be objects that are in the possession of other people or natural hard-to-reach objects. Not always a person can realize all her needs. Needs are much wider than possession. Actually the needs are aimed at increasing possession. How far can an individual's possession increase? Is it possible to indicate such a material object that will never be claimed by human? Obviously such an object cannot be specified. Any material object in the Universe can be claimed by human sooner or later. And even if not by human then by another intelligent being. Let's look at the stars, for example. It would seem that they are not reachable. But even now not even reaching them people already use stars. Since we see them it means that there is an interaction between stars and our bodies, we perceive their light. With help of other devices such as optical and radio telescopes, various traps for cosmic particles, etc., we can even increase their impact on us. In the physical sense, we are already using stars.

Thus, we can say that the needs of mankind, of a person as a species are not limited from above in the sense that, as said above, it is impossible to indicate such a material object, which would not be claimed now or in future. Are there any restrictions on some individuals? Apparently by upbringing or appropriate conditions or chemicals etc. many people can be severely limited in their needs in general and in certain specific needs in particular. In addition in some material objects people can experience zero needs without any special conditions and in everyday life, for example, in the waste that we regularly throw away. But again it cannot be said that waste cannot be claimed by anyone. Biological waste can be disposed of by someone with the receipt of fertilizers and energy and combustible gases. Municipal solid waste is also used for processing into useful substances and energy.

If to consider any arbitrary material object, it can be claimed by some person. Moreover it can be claimed by more than one person. In this case we have material objects the need for which two or more people experience or can experience at the same time. It is not difficult to see that due to the limitless human needs absolutely all material objects in the Universe fall under this criterion. Even if now some material objects are not claimed by a human then tomorrow or in a year or in a thousand years they can be claimed by someone. And even if now a material object is claimed by only one person, tomorrow it can be claimed by someone else. 
Let us compare this criterion with the existing definitions and ideas about the concept of property, which were mentioned above. One can see that this criterion completely overlaps the relationship between people and things through needs, as well as the relationship between people because of things due to the clash of the needs of different people on one thing. That is needs are a connecting quality between a person and a thing, and at the same time between people because of a things. Despite the temptation, as mentioned above, we will not define property by this criterion although it begs it. The main objection is that this criterion does not answer the question of the affiliation of material objects.

\section{Whose is this?}

As for the rights or methods of appropriation, the necessary condition for them is a sufficiently large and somehow organized society. And the rights and the method of appropriation must be provided with the necessary social strength, social mechanisms. At the same time, the question "whose is it?" arises even in the absence of a large society. It's enough even two people claiming on the same thing (experiencing the need for the same material object). This suggests that for the description and solution of the issues of social life, more general, more fundamental concepts should be involved than rights.

Let us consider how can be solved this simple question "whose is it?" but with not simple consequences. First of all we consider the case of two people experiencing the need for the same material object. There are nobody else and they will decide between them whose an object is.

Since usage of object involves implementing its certain physical states or a sequence of states there may be cases when these two individuals need the same states of the object and when they need different states. In the first case it is possible to fulfill the needs of both individuals simultaneously without infringing on anyone. As a result one of the possible options is an agreement between them on joint ownership and/or use of a material object. I.e. co-ownership is implied.

People may not agree on sharing of use and possession in a situation where several individuals need different states of the object at the same time or even the same ones but using or possessing the object by one person leads to undesirable consequences for other. The reason for this may even be simply unfriendly feelings. Also misunderstandings are possible because of different costs for the same use. Finally there are common cases where co-ownership cannot suit anyone. For example sombody hardly wants to share personal care products. How can one resolve the issue of ownership of an object outside of co-ownership? How to decide who will realize her needs in an object and who will not? Who will determine what forces and how to apply to an object in order to bring it into the necessary states for own benefit?

Obviously if someone does not use the object it means that she should for some reason abandon such use. There are not so many such reasons:

1. There is no need for this object and it is not assumed that the object will be needed in the future. This is the waste case described above. Zero benefit gives zero need.

2. Incompatibility of satisfying different needs at the same time.

a. Both objects give positive but different benefit.

b. Both objects give positive but different loses. In the event of a natural disaster, for example, a person saves herself first of all and relatives and friends abandoning the acquired goods.

3. In contrast to the rational and therefore systematizable reasons described above, non-material, spiritual incentives are possible too. This is philanthropy and compassion and helping those in need etc.

Option 1 does not fall under the case in question, since we consider that both individuals experience the need for an object. We will not consider option 3 either. Firstly, this motivation is not 
amenable to rational explanation and description. And even though option 3 is not uncommon, relying on it and creating on its basis some theoretical constructs regarding social life is not possible at least for modern society. If this motive is any significant in social life then how to explain the large-scale and widespread manifestations of violence in the historical past and present of mankind?

So, we consider option 2 as a motivation for one of the subjects to refuse claims to the disputed object. In addition we are interesting not only in rejecting of one individual from her claims for the object but also in connection of this refusal with presence of another individual. I.e. whether and how one individual influences (let's denote her as A) on the rejection of claims on the object of another individual (let's denote her as B). According to option 2, A may try to create conditions when, in his opinion, the benefits from the use of the object for $B$ cannot exceed the costs. Consider these costs in specific examples. Firstly it is a threat of action when A shows to B her intention (proposed actions) if $B$ does not abandon his claims on the object. It is assumed that the results of these actions will constitute the very costs. In this case B must be sure that the A has the ability to perform her intentions. Otherwise the threat will not work. Secondly these are real actions that should provide costs for $B$, in the opinion of A. Since any action is the application of physical force to some object the first case falls under the definition of possession and the second falls under the definition of use. But neither one nor the other is impossible without the object of application of force. So at least one of individuals should already have some kind of physical object in possession and use. But we are only at the very beginning of answering question "whose is this?" This visible paradox can only be resolved in two cases. Firstly, if none of the individuals can perform actions that would force another individual to abandon claims on the object in question. But human practice refutes this with an uncountable number of cases when one person forces another to give up something. And it remains only to recognize that each person has in possession/use something that is given to her independently of anything. To understand what it is let's remove the very object from the case we are considering. Two individuals and their bodies will remain. And their bodies are the very material objects the use and possession of which a person has from birth.

So, our reasoning leads us to the fact that the answer to the question "whose is this?" regarding the affiliation of human bodies is decided by nature itself. But as mentioned above, a person can possess any material object including his own body only to a limited extent. The remaining limited possession may belong to nature and other people. This possibility A can use to influence $B$ and this is most evident in the absence of a third material object. Since we excluded from consideration the case when both individuals can agree on co-ownership, the use and/or possession of the body of the $B$ is carried out by $A$ without the consent of $B$. In was shown that any action without the consent of the owner must be followed by a response the purpose of which is to prevent the negative effect or consequences of this action [Vasiljev, 2019]. In our case B cannot fail to respond. Nevertheless A can decide on her actions with the body of $B$ if she considers that costs of the response will not exceed the expected benefits of possessing and using the body of B. We assume that a rational individual performs all her actions in order to maximize the utility, no matter how she understands this utility. In fact this is the same principle of causality when applied to human actions - nothing is done without a reason, each consequence has its own reason. Accordingly every human action has its own cause which is designated as utility in this case. In addition this definition assumes that the cause of human action may not always be seen to an outside observer and only the person herself can know it. We also assume that an economically rational individual performs all his actions in order to maximize economic utility for herself. In contrast to the previous definition economic utility is available for observation and can be objectively described, for example, by the amount of possession.

Returning to our $A$ and $B$, according to the definition, it can be argued that an economically rational individual will always decide on his actions with the body of $B$ if the costs of the response do not exceed the expected benefits of possessing and using the body of B. In other words if we consider the 
economically rational behavior then at the very beginning, at the very sources the answer to the question "Whose is this?" is decided by force and only by force. If the forces are such that the estimated costs do not allow any of the individuals to claim possession and use of the body of the other without consent then a situation arises when they both refuse from such claims. And this looks like a kind of contract either by default or by voiced or even by written agreement. If the alignment of forces allows one individual to seize some part of possession of the body of another then again the boundary of such a capture will be determined by increasing resistance and accordingly increasing costs. As a result both individuals will in fact abandon their claims outside the established border. Similarly one can consider the interaction of two individuals with respect to any other object other than their body.

Thus the individual's refusal to possess and use the material object is determined by the costs, which are power actions of another individual.

Now let's introduce the third individual C. Even without some other objects besides their own bodies, variants are possible that include various kinds of co-ownership. If the forces of all three are approximately equal then the two united are obviously stronger than one and can get a part of the possession of body of third in their common possession. Since there are three individuals there will also be three options for such an agreement: between $A$ and $B$, between $A$ and $C$, between $B$ and $C$. Various nuances are possible in the form of a break of old agreements and conclusion of new ones. If in the variant of two individuals the agreement on the division of possessions occurs as the limit of a forceful decision, then in the variant with three individuals the forceful decision is preceded by an agreement between the two and only after the redistribution of ownership the agreement between the three.

The notorious task of three or more bodies. It is possible that in relation to social relations it presents a non-trivial problem too. But I will hypothesize that under certain conditions the task of many bodies should lead to a simple solution, namely, to minimize the cost/benefit ratio, everyone should abandon claims to possess and use the bodies of others without their consent. One of the conditions is the complete uncertainty of the intentions of others. Another condition is that getting the body of another person into full possession and use is impossible physically. Some physiological functions a person herself can perform and nobody except her as well as to receive sensations from performing various body exercises. And this means that even if two people get limited control over the body of the third, then the share of each or at least the share of one of them is obviously less than half. At the same time, being in the role of the victim a person can lose significantly more than half of the possession of her body. I.e. the gain does not reach half of the possession of another's body while the loss may amount to more than half of the possession but already of your body. A condition can be formulated as follows: half owning your body is always more valuable than half owning someone else's body.

In the absence of rigorous evidence we will use as a hypothesis the assertion that a rational individual should choose to renounce claims to use and possess the bodies of others as an indispensable condition for others not to pretend to her body.

Here we come to the concept of refusal to possess/use a physical object by everyone except the one who is recognized as its owner. The owner as a result receives the right to use the object. l.e. the right of one is the refusal of all others.

Definition 4 (D4). The right to use or the right to possess is the refusal of all other people respectively to use or possess the object in favor of who will be the actual owner.

It should be noted that in real life the rationality of an individual does not always take place. For example a rational individual will not play the lottery since the probability of losing is obviously higher than the probability of winning. The same applies to gambling and other events with a forseen probability loss. However people practicing these kinds of activities are abundant in a modern rather enlightened society. And probability of encroachment on their bodies hardly stop such people. This means that condition for refusing to infringe on others is a necessary but not sufficient. 
For additional motivation of people from an encroachment on other's the use or threat of the use of force is required; the force which a person will not be able to oppose anything. An example of such motivation is given by the whole history of mankind. The community of people as a rule allows opposing its individual members with significantly greater power forcing them to obey the rules established in society. Actually communities are often organized precisely to counter attacks on someone else's, including from some members of the community in relation to other members of the community.

The reasoning described above regarding the affiliation of the human body is valid for individuals that have the ability to exercise force against other entities. As a rule these are capable and quite mature individuals. In addition there are also dependents and children and other incapable members of society. Already from the fact that they cannot independently assert their right to use and possess their body, it follows that they will somehow be infringed on their rights in comparison with other members of society. I.e. the rights to their bodies should somehow be distributed between the society, capable members of the society and the dependents themselves. Apparently an unambiguous theoretical solution does not exist here and this is a matter of agreements between capable members of society. But the question of a theoretical definition of the border distinguishing incapable members of society still has a solution. This will be discussed below.

In addition to the human body for which the nature itself determined the rules of possession and use there is another resource for which the nature again defines the rules of possession and useThese are natural resources. No one created them and no one invested their work in them and no one individually can count on their unconditional possession. There are no grounds on which all other people would voluntarily abandon them in favor of one or more people. There is also no reason that in the case of sharing resources between people some of them would give up claims for the other's share if in their opinion it is larger than their own since there are no reasonable criteria for comparison, for example, a land in a city and somewhere in tundra. Thus it is impossible without violence neither to share resources between all people in the community fairly or evenly nor allow only parts of the community to possess them. The only solution to resolve these contradictions is to recognize that resources can be co-owned at that equally by all members of the community. Only on these grounds a person can abandon her claims to share of another because in this case she will no longer have any reason to believe that someone has more possession than she has (only resources are meant).

It should be noted that the previous arguments relate primarily to relations within the existing state formations because declaring their rights to a certain territory the population of a given country can justify its claims by the inheritance of its ancestors who tried to ensure that the territory of the state was as it is. Perhaps in the distant future humanity will consider all resources as the joint possession of all people regardless of belonging to different states but then the states themselves will disappear. Now this is not actually to talk about. True there are already territories that are considered as joint possession of mankind, for example, Antarctica. It is possible that the newly developed territories whether on earth or in the ocean or on other planets will also be under the aegis of all mankind.

So the nature provided us by its laws which determine possession and use. The human body belongs to human herself and natural resources belong to all people equally. This concludes the issue of initial appropriation. Everything else that is created by people on the basis of initial resources can be unambiguously affiliated within the framework of contractual relations, which allows us to exhaustively answer the question "Whose is this?".

\section{Co-ownership}

Let's now consider the aforementioned case of co-ownership, i.e. when two or more individuals can agree on the joint possession and use of certain tangible objects. As in sole possession in coownership there may be cases when the necessary states of the co-owned object are realized by 
applying physical forces directly using only bodies of co-owners. This can be pulling of seine from the water or tug-of-war or riding a tandem bicycle, etc. But often such use of the object of co-ownership is physically impossible. Enough numerous shareholders of any commercial enterprise cannot together turn the lathe handles together or switch circuit breakers or operate with other devices and equipment that make up the objects of co-ownership. To use these objects co-owners need a mechanism other than the application of their own physical efforts to the object of co-ownership. This mechanism is voting. By means of voting co-owners draw up their agreements regarding the laws and rules for the use of objects of co-ownership also forms and methods of control over compliance with these rules, as well as the procedure for revising existing agreements. By voting the charter (fundamental law) of the coowners' company is approved. Through voting the head of the executive institution for the use of coownership objects (director, general director, president, etc.) is hired and approved. Further, the head of the executive institution guided by the charter adopted by the co-owners and job descriptions and other regulations organizes the use of co-ownership facilities in accordance with the goals that were adopted by the co-owners. And if the head of the executive institution does not fulfill the obligations assigned to her properly the question of her removal is again decided by the vote of the co-owners.

Co-ownership takes place not only in commercial enterprises such as joint stock companies. The question of natural resources discussed above can be solved just in the framework of co-ownership. A feature of such co-ownership is that each co-owner has the same share in the property as other coowners. Here we come to the definition of what is called democracy in politics and in everyday life. From the point of view of possession and use the democracy is a form of co-ownership in which all coowners have equal shares in the property.

In 1951, K.J. Arrow proved a theorem known as the Arrow's Impossibility Theorem. In 1963, the second edition of his work was published [Arrow]. And in 1972, Arrow won the Nobel Prize for economics as a reflection of the recognition of his work and the importance of the main conclusion of his theorem that there are no and cannot be voting schemes that correctly determine the collective opinion of people. As applied to society it is also a conclusion about the impossibility of ideal democracy.

It would seem that Arrow's theorem puts an end to the search for a theoretical solution to democracy and co-ownership consequently. Arrow's theoretical constructions and his theorem, in particular, are based on the so-called an ordinal approach in which preferences can be measured only qualitatively rather than quantitatively. For example, alternative A can only be better or worse than alternative $B$ but it cannot be more or less. Since in everyday life there is both a qualitative and a quantitative measurement of preferences, a significant argument in favor of the ordinal approach in theoretical constructions is the assertion that such an approach is sufficient to describe all conceivable cases and that other approaches are simply not needed. Another the cardinal approach which implies measurability of preferences seems to make no sense. However the main conclusion of Arrow's theorem is called into question [Vasiljev, 2014] precisely on the basis that the ordinal approach does not allow to describe all conceivable and even widely used in practice preference aggregation rules. On examples of judging in sports competitions such as freestyle and diving and trampolining and figure skating, etc., it is shown that the aggregation schemes of judge's preferences cannot be described in the framework of the ordinal approach. Whereas the cardinal approach allows to describe the voting data. Moreover it is shown in disprove of Arrow's theorem that if all the conditions of Arrow's theorem are fulfilled cardinal voting can correctly determine the collective opinion of people.

\section{Features of possession and use the human body}

The human body is a material object as any other. It consists of atoms and molecules, and like any other material object the human body is in possession and use. Human has only limited control over his body. Some part of the possession the nature has. Also other people can own and use the human body. 
First of all it concerns incapable members of society. They are not ready for an independent life in society and therefore on the one hand other members of the society take responsibility for caring for the body of an incapable individual (parents, guardians), and on the other hand they restrict an incapable individual from actions that are undesirable for society (again parents and guardians as well as various social structures).

A showcase of incapable individuals is children. Just born children without outside help cannot even survive. Growing up they learn the language and other communication skills with other people, including coevals. In many societies the age threshold for the transition from incapability to legally capable members of the society with some medical restrictions has been adopted. It is assumed that by a certain age a person receives all the necessary skills for independent living in society. And when a person reaches this age, parents and society REFUSE a significant part of their possession and use that they had regarding the body of this person. Not all possession and use because a person living in society is subject to the laws of society which prohibit certain actions of a person limiting him in the possession and use of his body. This possession remains with society.

The age criterion for determining legal capacity seems to be insufficiently correct. It was shown above that the right [of possession and use] of one imply the refusal of all others from possession and use of something. Accordingly, when a new member of society comes into her own, all other members refuse to possess and use her body and other things recognized by society as her. But the new member of society herself must also abandon her claims to tangible objects recognized by society belonging to other in order to be an equal member of the society. l.e. by the time she enters into full membership in society a person must have certain knowledge about the laws of society, about ownership, use, rights, as well as be aware of the consequences of violating these laws and the penalties for such violations. The fact that far from all who have reached the age of capability fully possess such knowledge and are aware of their measure of responsibility is evidenced by crime in society. A person who performs actions with other's material objects without the consent of the owner clearly demonstrates that she did not give up her claims on them. When punishing such a person society, as a rule, restricts her rights [to possess and use both other's things and her own] when, for example, imprisons them in correctional institutions. These people have reached the age of majority but nevertheless they are limited in their legal capacity. And the criterion for this restriction is the refusal to recognize certain material objects as belonging to other people. So why not to use this criterion at the stage of entering into legal capacity, for example, in the form of passing an exam similar to examinations for knowledge of all other academic disciplines?

And few remarks to complete the discussion about the possession and use of the human body. As mentioned above, the human body is a material object as any other and it is also in possession and use. We above found out that the body of a capable person should belong to the person herself. But human is free to dispose of his body as well as any other of her belonging. I.e. she can transfer part of possession of her body to other people on a contractual basis. A very common case when a person is hired. The employer needs to perform some actions with her material objects in order to obtain the states of these objects that she needs. She can do it herself but she can also take advantage of the efforts of other people if she can offer them something in return that is necessary for them. As a rule money is the universal equivalent of payment for labor. In exchange for money the employer receives in limited use the body of the employee with knowledge and skills. For the duration of the work the employee undertakes to perform only those actions with her body that are agreed upon by the contract, i.e. the actions that the employer needs and for which she actually pays the employee. Theoretically, the employer uses her material objects applying physical forces to them through other physical bodies (workers) which for the time and on the terms of the employment contract are also in her limited possession and use. 
In addition to hiring, there are less obvious cases when a person transfers the use and possession of her own body to other people. For example, when marring people transfer to each other a part of possession of their own bodies. Participating in yard games and various social events people agree to some restrictions on the use of their bodies which are determined by the rules of the events. These possessions temporarily pass to the society within which the event is held. Meetings and elections polls and referenda in various societies and states are also events requiring a person to transfer a part of possession of her body to society for the duration of her participation in the event.

\section{References}

1. Abraham Bell and Gideon Parchomovsky, A Theory of Property, Cornell Law Review, Vol. 90, p. 531, 2005, U of Penn, Inst. for Law \& Econ Research Paper 04-05.

2. Thomas W. Merrill \& Henry E. Smith, What Happened to Property in Law and Economics?,111 Yale L.J. 357, 357 (2001).

3. A.M. Honore, Ownership, in Oxford Essays in Jurisprudence 107 (A.G. Guest ed., 1961)

4. Civil right of Russia. Part one. Edited by Z.I. Tsibulenko. Moscow: Jurist. 1998. In Russian.

5. Marx, Karl; Engels, Friedrich (1992). Collected Works. 46. London. ISBN 9780853156222.

6. Vasiljev, Sergei A. The Newton's Third Law in Social Relations// History, political science, sociology, philosophy: theoretical and practical aspects. XXIV-XXV international conf. № 910(17). - Novosibirsk: SibAC, 2019. - P. 46-54.

7. Arrow, Kenneth J. Social Choice and Individual Values. New York: Wiley, 1951.

8. Arrow, Kenneth J. Social Choice and Individual Values, 2nd Ed. New York: Wiley, 1963.

9. Vasiljev, Sergei A. Cardinal Voting: the Way to Escape the Social Choice Impossibility. Young Scientist USA. Social Science. Lulu, 2014. 